\title{
Study on Thermodynamic Properties for Binary Systems of Water + L-Cysteine Hydrochloride Monohydrate, Glycerol, and D-Sorbitol at Various Temperatures
}

\author{
F. Koohyar, ${ }^{1}$ A. A. Rostami, ${ }^{2}$ M. J. Chaichi, ${ }^{2}$ and F. Kiani ${ }^{3}$ \\ ${ }^{1}$ Department of Chemistry, Faculty of Science, Babol Branch, Islamic Azad University, Babol, Iran \\ ${ }^{2}$ Faculty of Chemistry, University of Mazandaran, Babolsar, Iran \\ ${ }^{3}$ Department of Chemistry, Faculty of Science, Ayatollah Amoli Branch, Islamic Azad University, Amol, Iran
}

Correspondence should be addressed to F. Koohyar; fardadkoohyar@yahoo.com

Received 11 June 2012; Revised 26 July 2012; Accepted 9 August 2012

Academic Editor: Christophe Coquelet

Copyright (C) 2013 F. Koohyar et al. This is an open access article distributed under the Creative Commons Attribution License, which permits unrestricted use, distribution, and reproduction in any medium, provided the original work is properly cited.

\begin{abstract}
Viscosities, refractive indices, and densities for aqueous solution of L-cysteine hydrochloride monohydrate ([LCHCMH]) and Dsorbitol, and also densities $(\rho)$, refractive indices $\left(n_{D}\right)$, excess molar volumes $\left(V^{E}\right)$, and change of refractive indices on mixing $\left(\Delta n_{D}\right)$ for aqueous solution of glycerol have been measured at several mole fractions and temperatures (between $T=303.15 \mathrm{~K}$ and $T=323.15 \mathrm{~K}$ ) at atmospheric pressure. The measurements were carried out using a vibrating-tube density meter for density, an Abbe refractometer for refractive index, and an Ubbelohde viscometer for viscosity. From these data for aqueous solution of glycerol, the excess molar volumes and the change of refractive indices on mixing were calculated and fitted to the Redlich-Kister polynomial equation. Also for aqueous solutions of [LCHCMH], glycerol, and D-sorbitol, the density and refractive indices were fitted with the experimental equations to estimate the adjustable parameters and relative deviations. It has been observed for aqueous solution of glycerol that the excess molar volumes and change of refractive indices on mixing increase and decrease with increasing temperature, respectively.
\end{abstract}

\section{Introduction}

Studies on the viscosity and density of binary mixtures along with other thermodynamic properties are being increasingly used as tools for the investigation of the properties of pure components and the nature of intermolecular interactions between liquid mixture components [1]. Also the thermodynamic properties of aqueous solutions play a very important role in variety of fields: chemistry and chemical engineering, separation process (crystallization, evaporation, and desalination), wastewater treatment, pollution control, and oil recovery $[2,3]$. Aqueous solutions of alcohols and polyols have attracted a good deal of attention of the scientific community for decades for their unusual nonideal behavior, especially in the low-concentration range. Besides, their study gives important information about the nature of interactions between nonpolar and polar groups with water and how these interactions affect the balance between hydrophobic and hydrophilic effects [4-7].
Hydrogen-bonded systems are very interesting because hydrogen bonds play a vital role in chemical, physical, and biological processes. D-sorbitol, water, and glycerol molecules have strong hydrogen bonds [8].

The L-cysteine is one of the essential amino acids for body and is found in the blood, hair, and some plants such as, soya (antioxidant). [LCHCMH] is a salt of this amino acid that is very soluble in water and is used in the medical industry [13]. One of the reasons for dissolving of D-sorbitol in water is that it has six $\mathrm{OH}$ groups and production of hydrogen bonds between water molecules and these groups. The molecule structure of D-sorbitol is similar to glucose but the solubility of D-sorbitol in water is higher. The measured data for aqueous solution of D-sorbitol play an important role in the fields of food engineering, food and medical industry [1416], fragile biological material processing, and in the study of inhibitor of the formation of gas hydrate because sugars and polyalcohols exhibit a substantial inhibiting effect on hydrate formation $[17,18]$. Glycerol is one type of alcohol that is very 
TABLE 1: Experimental value of density $(\rho)$ and refractive index $\left(n_{D}\right)$ of pure liquids along with the corresponding values available in the literature at various temperatures $(\mathrm{K})$.

\begin{tabular}{lccccc}
\hline \multirow{2}{*}{ Liquid } & $T(\mathrm{~K})$ & \multicolumn{2}{c}{$\rho\left(\mathrm{g} / \mathrm{cm}^{3}\right)$} & & $n_{D}$ \\
& & Experimental & Literature & Experimental & 1.3320 \\
Later & 303.15 & 0.9957 & $0.99565^{\mathrm{a}}$ & 1.3305 & $1.3319^{\mathrm{b}}$ \\
& 313.15 & 0.9922 & $0.99221^{\mathrm{a}}$ & 1.3290 & $1.3290^{\mathrm{b}}$ \\
\hline \multirow{3}{*}{ glycerol } & 323.15 & 0.9880 & $0.98804^{\mathrm{b}}$ & 1.4710 & not available \\
& 303.15 & 1.2557 & $1.25560^{\mathrm{c}}$ & 1.4670 & not available \\
& 313.15 & 1.2493 & $1.24950^{\mathrm{c}}$ & 1.4640 & not available \\
\hline
\end{tabular}

aef. [9].

${ }^{\mathrm{b}}$ Ref. [10].

${ }^{\mathrm{c}}$ Ref. $[11,12]$.

soluble in water. It can be due to having three $\mathrm{OH}$ groups. Glycerol is using in the pharmaceutical, cosmetic, and food industries because it is nontoxic and possesses good solvent properties for many compounds, both organic and inorganic $[19,20]$. It has useful solvent properties, similar to those of water and simple aliphatic alcohols, because it has three alcoholic groups [12]. One of the uses of aqueous solution of [LCHCMH] is in the microbial cultures. Aqueous solution of $\mathrm{D}$-sorbitol is used in the artificial sweeter and some kinds of drugs. Aqueous solution of glycerol is used as a softener in cosmetics and drugs, also antifreeze products. Therefore, the study on thermodynamic properties of aqueous solution of D-sorbitol, [LCHCMH], and glycerol in several temperatures can be used in different industries.

\section{Experimental}

2.1. Materials. D-sorbitol, [LCHCMH], and glycerol were purchased from Merck Co. (Darmstadt, Germany). The purity of D-sorbitol and glycerol is $98 \%$ and purity of $[\mathrm{LCHCMH}]$ is $99 \%$. They are used without further purification. All dilute solutions were prepared from double-distilled water with specific conductivity equal to $1.3 \pm 0.1 \mu \Omega^{-1} \cdot \mathrm{cm}^{-1}$.

2.2. Apparatus and Procedure. All solutions were prepared by weighing suitable amounts of the individual components and mixed in a beaker. The mixtures were transferred into stopper reagent bottles to prevent water evaporation. All of the experiments are repeated three times and average values are reported. For weighting of solutes a balance (Precisa $240 \mathrm{~A}$, Switzerland) was used with a precision of $\pm 0.0001 \mathrm{~g}$. Densities $(\rho)$ were measured using a digital vibrating glass tube densimeter (DA-500E, China.). Before each series of measurements, the instrument was calibrated at atmospheric pressure with double-distilled water and dry air. Densities were determined with an uncertainty of $\pm 1 \times 10^{-4} \mathrm{~g} \cdot \mathrm{cm}^{-3}$. The dynamic viscosity $(\eta)$ of the pure components and mixtures was determined from the kinematic viscosities $v$ measured using an Ubbelhode viscometer with automatic measuring unit (Schott, AVS 400, Germany). Four Ubbelohde tubes with different capillary size $(0.36,0.46,0.53$, and $0.63 \mathrm{~mm})$ were used in the experiments according to the different viscosities of the mixtures. For all measurements, a SchottGerate CT 1150 digital thermostat was used to control the temperature within $\pm 0.01 \mathrm{~K}$ of the desired temperature. The uncertainty of the time measurement in the viscometer is $\pm 0.01 \mathrm{~s}$. Refractive indices for the sodium $D$-line $n_{D}$ were measured with an Abbe refractometer (Carl Zeiss, Model A, Germany). A minimum of three independent readings was taken for each composition. The uncertainties of the refractive index and dynamic viscosity are $\pm 1 \times 10^{-4}$ and $0.003(\% 0.3) \mathrm{mPa} \cdot \mathrm{s}$, respectively. Also the uncertainty of the temperature is $\pm 0.01 \mathrm{~K}$.

\section{Results and Discussion}

The experimental data of densities $(\rho)$, refractive indices $\left(n_{D}\right)$, and dynamic viscosities $(\eta)$ for aqueous solution of [LCHCMH] and D-sorbitol at $(303.15,308.15,313.15,318.15$ and 323.15$) \mathrm{K}$, also densities $(\rho)$, refractive indices $\left(n_{D}\right)$, excess molar volumes $\left(V^{E}\right)$, and change of refractive indices on mixing $\left(\Delta n_{D}\right)$ for aqueous solution of glycerol at (303.15, 313.15 , and 323.15) $\mathrm{K}$ are listed in Tables 2 and 3. The densities and refractive indices of pure water and glycerol at different temperatures are listed in Table 1.

The value of $V^{E}$ for aqueous solution of glycerol was calculated from the density data using:

$$
V^{E}=\frac{\left(x_{1} M_{1}+x_{2} M_{2}\right)}{\rho}-\left(\frac{x_{1} M_{1}}{\rho_{1}}+\frac{x_{2} M_{2}}{\rho_{2}}\right) .
$$

In this equation $x_{1}, x_{2}$ are mole fractions, $M_{1}, M_{2}$ are the molar masses, and $\rho_{1}, \rho_{2}$ are the densities of pure components 1,2 , respectively.

The change of refractive index on mixing $\left(\Delta n_{D}\right)$ for aqueous solution of glycerol was calculated from:

$$
\Delta n_{D}=n_{D}-\left(x_{1} n_{D 1}+x_{2} n_{D 2}\right) .
$$

In this equation $x_{1}, x_{2}$ are mole fractions, $n_{D}, n_{D 1}, n_{D 2}$ are the refractive indices of the mixture and the pure components 1 , 2 , respectively.

The values of $\Delta n_{D}$ and $V^{E}$ for aqueous solution of [LCHCMH] and D-sorbitol cannot be calculated directly because for the calculation of $\Delta n_{D}$ and $V^{E}$ for mixture we need the refractive indices and densities of the pure 
TABLe 2: Experimental densities $(\rho)$, viscosities $(\eta)$ and refractive indices $\left(n_{D}\right)$ as functions of mole fraction of [LCHCMH] and D-sorbitol $\left(x_{1}\right)$ for binary systems of [LCHCMH] (2) + water (1) and D-sorbitol (2) + water (1) at the various temperatures (K) and atmospheric pressure.

\begin{tabular}{|c|c|c|c|c|c|c|c|}
\hline$x_{1}$ & $\rho\left(\mathrm{g} / \mathrm{cm}^{3}\right)$ & $\eta(\mathrm{mPa} \cdot \mathrm{s})$ & $n_{D}$ & $x_{1}$ & $\rho\left(\mathrm{g} / \mathrm{cm}^{3}\right)$ & $\eta(\mathrm{mPa} \cdot \mathrm{s})$ & $n_{D}$ \\
\hline \multicolumn{4}{|c|}{ [LCHCMH] (2) + water (1) } & \multicolumn{4}{|c|}{ D-sorbitol (2) + water (1) } \\
\hline \multicolumn{8}{|c|}{$T=303.15 \mathrm{~K}$} \\
\hline 0.010 & 1.0252 & 0.8529 & 1.3480 & 0.002 & 0.9982 & 0.8134 & 1.3340 \\
\hline 0.020 & 1.0534 & 1.1265 & 1.3605 & 0.004 & 1.0063 & 0.8647 & 1.3370 \\
\hline 0.040 & 1.0988 & 1.5062 & 1.3830 & 0.006 & 1.0138 & 0.9160 & 1.3400 \\
\hline 0.080 & 1.1637 & 2.4858 & 1.4175 & 0.008 & 1.0210 & 0.9675 & 1.3425 \\
\hline 0.100 & 1.1903 & 3.3911 & 1.4310 & 0.010 & 1.0278 & 1.0191 & 1.3455 \\
\hline 0.110 & 1.2029 & 3.9700 & 1.4370 & 0.012 & 1.0342 & 1.0708 & 1.3480 \\
\hline 0.120 & 1.2151 & 4.6266 & 1.4425 & 0.014 & 1.0401 & 1.1226 & 1.3505 \\
\hline 0.130 & 1.2268 & 5.3488 & 1.4475 & 0.016 & 1.0457 & 1.1745 & 1.3530 \\
\hline 0.140 & 1.2378 & 6.1192 & 1.4525 & 0.018 & 1.0508 & 1.2266 & 1.3550 \\
\hline 0.150 & 1.2478 & 6.9147 & 1.4570 & 0.020 & 1.0554 & 1.2787 & 1.3570 \\
\hline 0.160 & 1.2562 & 7.7061 & 1.4615 & 0.022 & 1.0598 & 1.3310 & 1.3590 \\
\hline 0.170 & 1.2643 & 8.4592 & 1.4660 & 0.024 & 1.0636 & 1.3834 & 1.3605 \\
\hline 0.180 & 1.2715 & 9.1336 & 1.4700 & 0.026 & 1.0671 & 1.4359 & 1.3625 \\
\hline 0.190 & 1.2765 & 9.9717 & 1.4740 & 0.028 & 1.0702 & 1.4885 & 1.3640 \\
\hline \multicolumn{8}{|c|}{$T=308.15 \mathrm{~K}$} \\
\hline 0.010 & 1.0234 & 0.7892 & 1.3472 & 0.002 & 0.9962 & 0.7471 & 1.3335 \\
\hline 0.020 & 1.0509 & 1.0228 & 1.3597 & 0.004 & 1.0048 & 0.7869 & 1.3365 \\
\hline 0.040 & 1.0962 & 1.3563 & 1.3819 & 0.006 & 1.0122 & 0.8221 & 1.3394 \\
\hline 0.080 & 1.1613 & 2.2369 & 1.4164 & 0.008 & 1.0195 & 0.8763 & 1.3420 \\
\hline 0.100 & 1.1866 & 2.9551 & 1.4300 & 0.010 & 1.0253 & 0.9231 & 1.3447 \\
\hline 0.110 & 1.1983 & 3.3869 & 1.4360 & 0.012 & 1.0312 & 0.9658 & 1.3471 \\
\hline 0.120 & 1.2093 & 3.8827 & 1.4415 & 0.014 & 1.0376 & 1.0081 & 1.3497 \\
\hline 0.130 & 1.2198 & 4.4510 & 1.4464 & 0.016 & 1.0428 & 1.0535 & 1.3520 \\
\hline 0.140 & 1.2298 & 5.1008 & 1.4514 & 0.018 & 1.0482 & 1.1053 & 1.3543 \\
\hline 0.150 & 1.2391 & 5.8416 & 1.4560 & 0.020 & 1.0526 & 1.1472 & 1.3562 \\
\hline 0.160 & 1.2467 & 6.5236 & 1.4606 & 0.022 & 1.0570 & 1.2027 & 1.3580 \\
\hline 0.170 & 1.2543 & 7.2175 & 1.4647 & 0.024 & 1.0615 & 1.2453 & 1.3600 \\
\hline 0.180 & 1.2611 & 8.0144 & 1.4690 & 0.026 & 1.0648 & 1.2914 & 1.3615 \\
\hline 0.190 & 1.2658 & 8.8263 & 1.4730 & 0.028 & 1.0676 & 1.3555 & 1.3632 \\
\hline \multicolumn{8}{|c|}{$T=313.15 \mathrm{~K}$} \\
\hline 0.010 & 1.0217 & 0.7275 & 1.3465 & 0.002 & 0.9948 & 0.6825 & 1.3330 \\
\hline 0.020 & 1.0491 & 0.9082 & 1.3590 & 0.004 & 1.0030 & 0.7202 & 1.3360 \\
\hline 0.040 & 1.0944 & 1.2733 & 1.3810 & 0.006 & 1.0102 & 0.7581 & 1.3385 \\
\hline 0.080 & 1.1588 & 1.9680 & 1.4155 & 0.008 & 1.0173 & 0.7961 & 1.3415 \\
\hline 0.100 & 1.1833 & 2.5717 & 1.4290 & 0.010 & 1.0236 & 0.8344 & 1.3440 \\
\hline 0.110 & 1.1944 & 2.9513 & 1.4350 & 0.012 & 1.0296 & 0.8728 & 1.3465 \\
\hline 0.120 & 1.2048 & 3.3866 & 1.4405 & 0.014 & 1.0354 & 0.9114 & 1.3490 \\
\hline 0.130 & 1.2146 & 3.8784 & 1.4455 & 0.016 & 1.0407 & 0.9502 & 1.3510 \\
\hline 0.140 & 1.2239 & 4.4260 & 1.4505 & 0.018 & 1.0459 & 0.9891 & 1.3535 \\
\hline 0.150 & 1.2326 & 5.0270 & 1.4550 & 0.020 & 1.0506 & 1.0282 & 1.3555 \\
\hline 0.160 & 1.2411 & 5.6776 & 1.4595 & 0.022 & 1.0549 & 1.0676 & 1.3575 \\
\hline 0.170 & 1.2478 & 6.3723 & 1.4635 & 0.024 & 1.0591 & 1.1071 & 1.3590 \\
\hline 0.180 & 1.2539 & 7.1039 & 1.4680 & 0.026 & 1.0628 & 1.1467 & 1.3610 \\
\hline 0.190 & 1.2591 & 7.8638 & 1.4720 & 0.028 & 1.0651 & 1.1866 & 1.3625 \\
\hline
\end{tabular}


TABle 2: Continued.

\begin{tabular}{|c|c|c|c|c|c|c|c|}
\hline \multirow[t]{2}{*}{$x_{1}$} & $\rho\left(\mathrm{g} / \mathrm{cm}^{3}\right)$ & $\eta(\mathrm{mPa} \cdot \mathrm{s})$ & $n_{D}$ & $x_{1}$ & $\rho\left(\mathrm{g} / \mathrm{cm}^{3}\right)$ & $\eta(\mathrm{mPa} \cdot \mathrm{s})$ & $n_{D}$ \\
\hline & \multicolumn{3}{|c|}{ [LCHCMH] (2) + water (1) } & \multicolumn{4}{|c|}{ D-sorbitol (2) + water (1) } \\
\hline \multicolumn{8}{|c|}{$T=318.15 \mathrm{~K}$} \\
\hline 0.010 & 1.0203 & 0.6712 & 1.3457 & 0.002 & 0.9925 & 0.6283 & 1.3325 \\
\hline 0.020 & 1.0474 & 0.8248 & 1.3582 & 0.004 & 1.0012 & 0.6625 & 1.3353 \\
\hline 0.040 & 1.0924 & 1.1123 & 1.3802 & 0.006 & 1.0082 & 0.6978 & 1.3380 \\
\hline 0.080 & 1.1565 & 1.7845 & 1.4147 & 0.008 & 1.0152 & 0.7286 & 1.3408 \\
\hline 0.100 & 1.1803 & 2.2926 & 1.4282 & 0.010 & 1.0211 & 0.7647 & 1.3432 \\
\hline 0.110 & 1.1910 & 2.5753 & 1.4342 & 0.012 & 1.0270 & 0.7960 & 1.3458 \\
\hline 0.120 & 1.2015 & 2.9296 & 1.4397 & 0.014 & 1.0332 & 0.8293 & 1.3480 \\
\hline 0.130 & 1.2115 & 3.3496 & 1.4447 & 0.016 & 1.0382 & 0.8716 & 1.3502 \\
\hline 0.140 & 1.2205 & 3.8327 & 1.4497 & 0.018 & 1.0434 & 0.9013 & 1.3525 \\
\hline 0.150 & 1.2292 & 4.4079 & 1.4540 & 0.020 & 1.0477 & 0.9433 & 1.3545 \\
\hline 0.160 & 1.2375 & 5.0173 & 1.4584 & 0.022 & 1.0526 & 0.9822 & 1.3565 \\
\hline 0.170 & 1.2445 & 5.7185 & 1.4624 & 0.024 & 1.0564 & 1.0148 & 1.3581 \\
\hline 0.180 & 1.2491 & 6.3015 & 1.4668 & 0.026 & 1.0592 & 1.0604 & 1.3601 \\
\hline 0.190 & 1.2545 & 7.0022 & 1.4708 & 0.028 & 1.0628 & 1.0893 & 1.3615 \\
\hline \multicolumn{8}{|c|}{$T=323.15 \mathrm{~K}$} \\
\hline 0.010 & 1.0182 & 0.6181 & 1.3450 & 0.002 & 0.9908 & 0.5854 & 1.3320 \\
\hline 0.020 & 1.0459 & 0.7690 & 1.3575 & 0.004 & 0.9986 & 0.6131 & 1.3345 \\
\hline 0.040 & 1.0908 & 1.0179 & 1.3795 & 0.006 & 1.0059 & 0.6414 & 1.3375 \\
\hline 0.080 & 1.1538 & 1.5936 & 1.4140 & 0.008 & 1.0129 & 0.6702 & 1.3400 \\
\hline 0.100 & 1.1776 & 2.0479 & 1.4275 & 0.010 & 1.0194 & 0.6996 & 1.3425 \\
\hline 0.110 & 1.1885 & 2.3364 & 1.4335 & 0.012 & 1.0256 & 0.7295 & 1.3450 \\
\hline 0.120 & 1.1987 & 2.6703 & 1.4390 & 0.014 & 1.0313 & 0.7600 & 1.3470 \\
\hline 0.130 & 1.2084 & 3.0522 & 1.4440 & 0.016 & 1.0366 & 0.7910 & 1.3495 \\
\hline 0.140 & 1.2176 & 3.4831 & 1.4490 & 0.018 & 1.0415 & 0.8226 & 1.3515 \\
\hline 0.150 & 1.2261 & 3.9632 & 1.4530 & 0.020 & 1.0461 & 0.8547 & 1.3535 \\
\hline 0.160 & 1.2339 & 4.4916 & 1.4575 & 0.022 & 1.0502 & 0.8874 & 1.3555 \\
\hline 0.170 & 1.2408 & 5.0663 & 1.4615 & 0.024 & 1.0538 & 0.9206 & 1.3570 \\
\hline 0.180 & 1.2465 & 5.6846 & 1.4655 & 0.026 & 1.0571 & 0.9544 & 1.3590 \\
\hline 0.190 & 1.2506 & 6.3421 & 1.4695 & 0.028 & 1.0599 & 0.9887 & 1.3605 \\
\hline
\end{tabular}

components of this mixture. For the solid components such as D-sorbitol and [LCHCMH] the density, refractive index, and viscosity are not available in literature at different temperatures.

The value of $\Delta n_{D}$ or $V^{E}$ for each mixture was fitted to the Redlich-Kister polynomial equation according to [21]:

$$
Y=x_{1}\left(1-x_{1}\right) \sum_{i=0}^{n} A_{i}\left(2 x_{1}-1\right)^{i} \text {. }
$$

Here $Y=V^{E}$ or $\Delta n_{D}$ and $A_{i}$ are adjustable parameters and $x_{1}$ is the mole fraction.

In each case, the optimum number of coefficients $A_{i}$ was determined from an examination of the variation of the standard deviation:

$$
\sigma(Y)=\left[\frac{\sum\left(Y_{\mathrm{cal}}-Y_{\mathrm{exp}}\right)^{2}}{n-m}\right]^{1 / 2}
$$

where $n$ is the total number of experimental values and $m$ is the number of parameters.
For aqueous solution of glycerol the values of these parameters, $A_{i}$, along with the standard errors $(\sigma)$ are listed in Table 4.

The experimental data that are listed in Tables 2 and 3 and Figure 1 show that the density, viscosity, and refractive index at each experimental temperature increase as the mole fraction of solutions increases. In the case of each mole fractions of solute, the density, viscosity, and refractive index of solutions decrease with increasing temperature.

The thermodynamic property values for solutions of this study can be dependent on two factors. The first factor is the concentration of solutions. The second factor is the power of bonds between solvent and solute molecules (in solution) due to the values of polarity (dipole-dipole interaction and the hydrogen bonds) and electrical charge of solute molecules. The second factor is effective in excess thermodynamic properties [22].

For mixtures of this study the maximum values of density and refractive index are perceived for aqueous solution of [LCHCMH]. In this solution the second factor is very effective due to the electrical charge of ions of solute molecules $\left(\mathrm{Cl}^{-}\right.$and $\left.\mathrm{R}-\mathrm{NH}_{3}{ }^{+}\right)$. 
TABLE 3: Experimental densities $(\rho)$, refractive indices $\left(n_{D}\right)$, excess molar volumes $\left(V^{E}\right)$ and change of refractive indices on mixing $\left(\Delta n_{D}\right)$ as functions of mole fraction of glycerol $\left(x_{1}\right)$ for binary system of glycerol (2) + water (1) at the various temperatures $(K)$ and atmospheric pressure.

\begin{tabular}{|c|c|c|c|c|}
\hline$x_{1}$ & $\rho\left(\mathrm{g} / \mathrm{cm}^{3}\right)$ & $n_{D}$ & $V^{E}\left(\mathrm{~cm}^{3} / \mathrm{mol}\right)$ & $\Delta n_{D}$ \\
\hline \multicolumn{5}{|c|}{$T=303.15 \mathrm{~K}$} \\
\hline 0.000 & 0.9956 & 1.3320 & 0.0000 & 0.0000 \\
\hline 0.010 & 1.0070 & 1.3380 & -0.0170 & 0.0046 \\
\hline 0.021 & 1.0187 & 1.3440 & -0.0372 & 0.0090 \\
\hline 0.036 & 1.0330 & 1.3510 & -0.0629 & 0.0140 \\
\hline 0.047 & 1.0428 & 1.3560 & -0.0819 & 0.0175 \\
\hline 0.071 & 1.0631 & 1.3665 & -0.1266 & 0.0247 \\
\hline 0.099 & 1.0842 & 1.3770 & -0.1812 & 0.0312 \\
\hline 0.133 & 1.1053 & 1.3880 & -0.2261 & 0.0375 \\
\hline 0.175 & 1.1269 & 1.3995 & -0.2731 & 0.0432 \\
\hline 0.227 & 1.1489 & 1.4110 & -0.3192 & 0.0475 \\
\hline 0.294 & 1.1710 & 1.4230 & -0.3559 & 0.0502 \\
\hline 0.382 & 1.1928 & 1.4345 & -0.3675 & 0.0493 \\
\hline 0.439 & 1.2036 & 1.4405 & -0.3601 & 0.0475 \\
\hline 0.589 & 1.2250 & 1.4525 & -0.3082 & 0.0392 \\
\hline 0.692 & 1.2356 & 1.4585 & -0.2553 & 0.0303 \\
\hline 0.824 & 1.2460 & 1.4655 & -0.1673 & 0.0189 \\
\hline 1.000 & 1.2557 & 1.4710 & 0.0000 & 0.0000 \\
\hline \multicolumn{5}{|c|}{$T=313.15 \mathrm{~K}$} \\
\hline 0.000 & 0.9922 & 1.3305 & 0.0000 & 0.0000 \\
\hline 0.010 & 1.0034 & 1.3360 & -0.0162 & 0.0041 \\
\hline 0.021 & 1.0150 & 1.3420 & -0.0366 & 0.0086 \\
\hline 0.036 & 1.0290 & 1.3490 & -0.0592 & 0.0136 \\
\hline 0.047 & 1.0388 & 1.3540 & -0.0801 & 0.0171 \\
\hline 0.071 & 1.0588 & 1.3645 & -0.1228 & 0.0243 \\
\hline 0.099 & 1.0795 & 1.3745 & -0.1733 & 0.0305 \\
\hline 0.133 & 1.1003 & 1.3855 & -0.2161 & 0.0368 \\
\hline 0.175 & 1.1218 & 1.3970 & -0.2658 & 0.0426 \\
\hline 0.227 & 1.1435 & 1.4085 & -0.3100 & 0.0470 \\
\hline 0.294 & 1.1652 & 1.4200 & -0.3416 & 0.0494 \\
\hline 0.382 & 1.1868 & 1.4310 & -0.3535 & 0.0483 \\
\hline 0.439 & 1.1975 & 1.4370 & -0.3464 & 0.0466 \\
\hline 0.589 & 1.2187 & 1.4490 & -0.2952 & 0.0380 \\
\hline 0.692 & 1.2291 & 1.4540 & -0.2382 & 0.0290 \\
\hline 0.824 & 1.2393 & 1.4605 & -0.1450 & 0.0175 \\
\hline 1.000 & 1.2493 & 1.4670 & 0.0000 & 0.0000 \\
\hline \multicolumn{5}{|c|}{$T=323.15 \mathrm{~K}$} \\
\hline 0.000 & 0.9880 & 1.3290 & 0.0000 & 0.0000 \\
\hline 0.010 & 0.9991 & 1.3340 & -0.0160 & 0.0036 \\
\hline 0.021 & 1.0105 & 1.3400 & -0.0261 & 0.0081 \\
\hline 0.036 & 1.0244 & 1.3470 & -0.0572 & 0.0131 \\
\hline 0.047 & 1.0340 & 1.3520 & -0.0758 & 0.0167 \\
\hline 0.071 & 1.0538 & 1.3625 & -0.1175 & 0.0239 \\
\hline 0.099 & 1.0743 & 1.3720 & -0.1673 & 0.0296 \\
\hline 0.133 & 1.0950 & 1.3830 & -0.2116 & 0.0360 \\
\hline 0.175 & 1.1160 & 1.3945 & -0.2535 & 0.0419 \\
\hline 0.227 & 1.1375 & 1.4060 & -0.2965 & 0.0464 \\
\hline 0.294 & 1.1590 & 1.4170 & -0.3268 & 0.0484 \\
\hline 0.382 & 1.1804 & 1.4275 & -0.3369 & 0.0469 \\
\hline 0.439 & 1.1911 & 1.4335 & -0.3322 & 0.0452 \\
\hline 0.589 & 1.2120 & 1.4455 & -0.2744 & 0.0370 \\
\hline 0.692 & 1.2222 & 1.4495 & -0.2106 & 0.0270 \\
\hline
\end{tabular}


TABLe 3: Continued.

\begin{tabular}{lcccc}
\hline$x_{1}$ & $\rho\left(\mathrm{g} / \mathrm{cm}^{3}\right)$ & $n_{D}$ & $V^{E}\left(\mathrm{~cm}^{3} / \mathrm{mol}\right)$ & $\Delta n_{D}$ \\
\hline 0.824 & 1.2323 & 1.4560 & -0.1139 & 0.0157 \\
1.000 & 1.2428 & 1.4640 & 0.0000 & 0.0000 \\
\hline
\end{tabular}

TABLE 4: Redlich-Kister fitting coefficients $A_{\mathrm{i}}$ and the standard deviation $\sigma$ of $V^{E}$ and $\Delta n_{D}$ for aqueous solution of glycerol at various temperatures $(\mathrm{K})$.

\begin{tabular}{lcccccc}
\hline$T(\mathrm{~K})$ & Property & $A_{0}$ & $A_{1}$ & $A_{2}$ & $A_{3}$ \\
\hline \multirow{2}{*}{303.15} & $V^{E}\left(\mathrm{~cm}^{3} / \mathrm{mol}\right)$ & -1.3792 & -0.9382 & -0.3966 & 0.9522 & 0.049 \\
& $\Delta n_{D}$ & 0.4746 & -0.2054 & 0.0826 & 0.0989 & 0.001 \\
\hline \multirow{2}{*}{313.15} & $V^{E}\left(\mathrm{~cm}^{3} / \mathrm{mol}\right)$ & -1.3288 & -0.9510 & -0.2533 & 0.8318 & 0.016 \\
& $\Delta n_{D}$ & 0.1731 & 0.1120 & 0.0826 & 0.0558 & 0.001 \\
\hline \multirow{2}{*}{323.15} & $V^{E}\left(\mathrm{~cm}^{3} / \mathrm{mol}\right)$ & -1.2586 & -0.9996 & -0.0742 & 0.6850 \\
& $\Delta n_{D}$ & 0.1680 & 0.1197 & 0.0731 & 0.007 \\
& & & & 0.001 \\
\hline
\end{tabular}

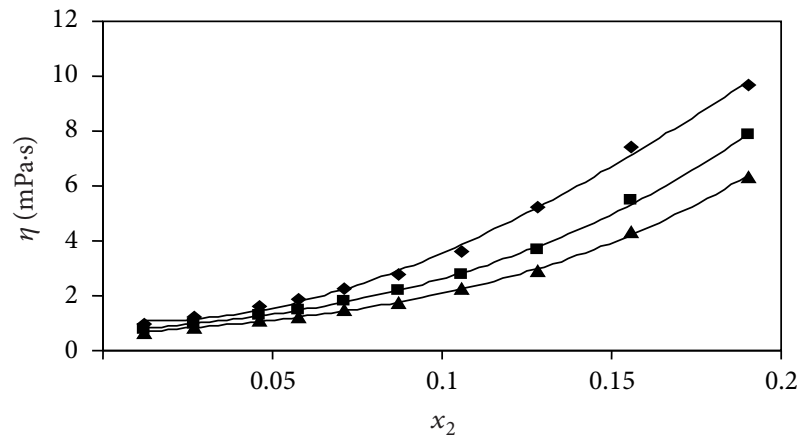

FIGURE 1: Variation of viscosities, $\eta$, against mole fraction of $[\mathrm{LCHCMH}], x_{2}$, for binary system of water $(1)+[\mathrm{LCHCMH}](2)$ at $T(\mathrm{~K})=\boldsymbol{\star}, 303.15 ; \mathbf{\square}, 313.15 ; \mathbf{\Delta}, 323.15$.

Also the minimum values of density and refractive index are perceived for aqueous solution of $\mathrm{D}$-sorbitol. In this solution the first factor is very effective due to a low concentration of solute in the solution.

Among the several thermodynamic properties, the excess molar volumes have been of much consideration for the practical target of determining composition from the density measurement. Excess molar volumes could also supply information on the possible interactions between components of a binary system, such as molecular associations and dipoledipole and dipole-induced-dipole interactions [23].

Three factors can be effective in the value of excess molar volumes $[24,25]$. The first factor is the specific forces between molecules, such as $\mathrm{H}$-bond and charge-transfer complexes. The positive excess molar volumes for the solution can be a result of the breaking of the H-bonds (weaker hydrogen bonds) and complexes between solvent and solute. Forming hydrogen bonds (stronger $\mathrm{H}$-bonds) and complexes bring negative values of excess molar volumes. The second factor is the physical forces between molecules including electrostatic forces between charged particles, permanent dipoles, induction forces between a permanent dipole and an induced dipole, forces of attraction (dispersion forces), and repulsion between nonpolar molecules. Physical forces

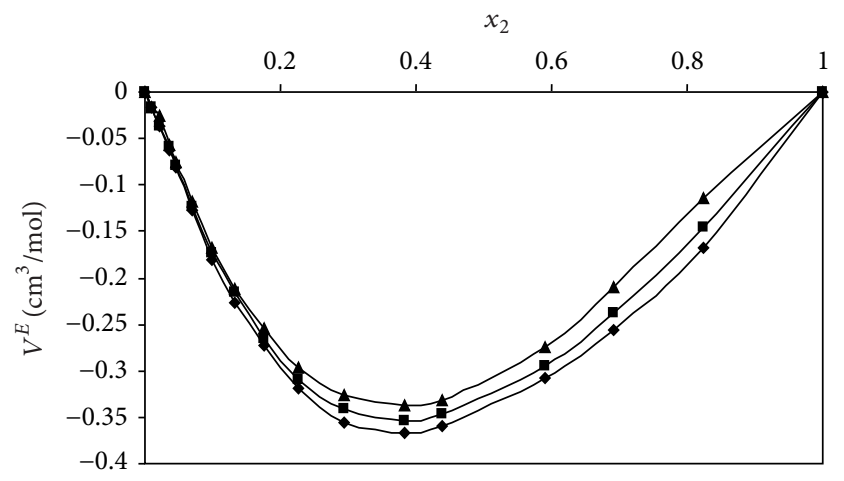

FIGURE 2: Variation of excess molar volumes, $V^{E}$, against mole fraction of glycerol, $x_{2}$, for binary system of water $(1)+$ glycerol (2) at $T(K)=\$, 303.15 ; \mathbf{\square}, 313.15 ; \mathbf{\Delta}, 323.15$.

between molecules are usually weak. The sign of excess molar volume values can be positive or negative but these absolute values are small. The third factor is the structural characteristics of the component, arising from geometrical fitting of one component into the other's structure, due to the differences in form and size of component and free volume.

As seen in Figure 2, the values of $V^{E}$ for aqueous solution of glycerol over the entire range of mole fractions at all experimental temperatures are negative. In this solution the third factor (the structural characteristics of the component, arising from geometrical fitting of one component into the other's structure) is very effective due to the small size of water molecules and better hydrogen bonding formation with three $\mathrm{OH}$ of glycerol and water [26].

The value of $V^{E}$ increases as the temperature increases. The distance between molecules in this solution increases with increasing of the temperature and the interaction between molecules in this solution decreases.

Also as seen in Figure 3, the values of $\Delta n_{D}$ for aqueous solution of glycerol over the entire range of mole fractions at all temperatures (in this study) are positive. The value of $\Delta n_{D}$ decreases as the temperature increases. 


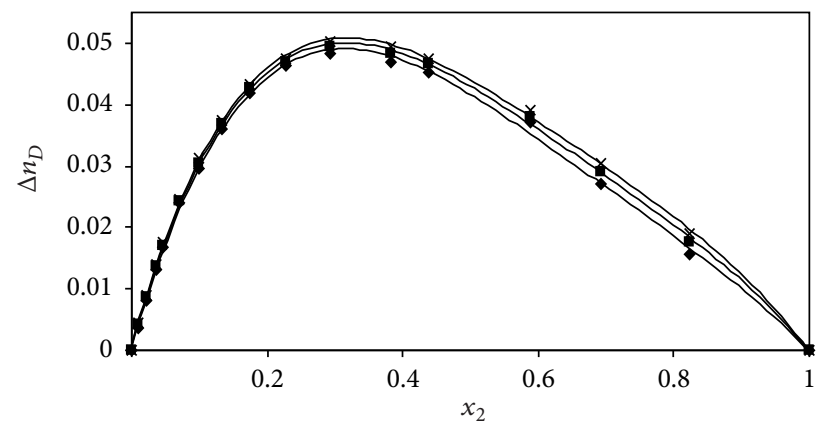

FIGURE 3: Variation of change of refractive indices on mixing, $\Delta n_{\mathrm{D}}$, against mole fraction of glycerol, $x_{2}$, for binary system of water (1) $+\operatorname{glycerol}(2)$ at $T(\mathrm{~K})=x, 303.15 ; \mathbf{\square}, 313.15 ; 323.15$.

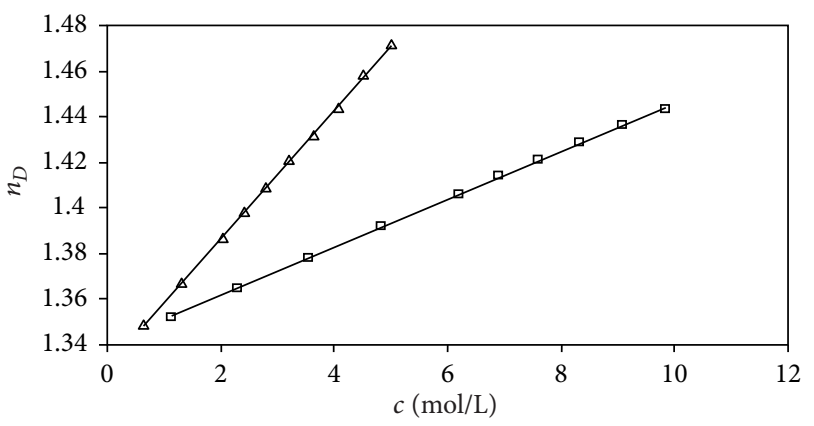

- Series 1, $y$ (series 1$)=0.0102 x+1.331, R^{2}=0.9997$

$\Delta$ Series $2, y$ (series 2$)=0.028 x+1.3309, R^{2}=0.9998$

Figure 4: The linearity between refractive indices, $n_{D}$, and molar concentration of [LCHCMH] and glycerol, $c$, at $T(\mathrm{~K})=313.15$ for binary systems of: $\square$, (glycerol + water); $\Delta$, ([LCHCMH] + water).

It is clear that the minimum and maximum values of $V^{E}$ and $\Delta n_{D}$ for aqueous solution of glycerol appear at $x_{\text {glycerol }} \approx$ 0.4 and $x_{\text {glycerol }} \approx 0.35$, respectively.

The refractive index $\left(n_{D}\right)$ for aqueous solutions obeys from the following equation [27]:

$$
n_{D}=A_{n} c+n_{D}^{*}
$$

where $n_{D}$ is the refractive index of aqueous solutions, $A_{n}$ is the constant that depends on physical and chemical properties of solute molecules, $c$ is the molar concentration of aqueous solutions, and $n_{D}^{*}$ is the refractive index of water at determinate temperature.

As seen in Figure 4, the correlation between refractive index and molar concentration for mixtures of this study is linear with high association coefficient $\left(R^{2}=0.9998\right)$ and we can obtain the value of constant $A_{n}$ for [LCHCMH] and glycerol solution at $313.15 \mathrm{~K}$ from this diagram according to $(5),\left[A_{n}[\mathrm{LCHCMH}]=0.0280 \mathrm{~L} \cdot \mathrm{mol}^{-1}\right.$ and $A_{n}[$ glycerol $]=$ $\left.0.0102 \mathrm{~L} \cdot \mathrm{mol}^{-1}\right]$.

For mixtures of this study, the values of $A_{n}, n_{D}^{*}$ and relative deviations between the experimental values of $n_{D}^{*}$ in literature (refractive index of water) [10], and calculated values of $n_{D}^{*}$ from (5) at different temperatures are listed in Table 5.

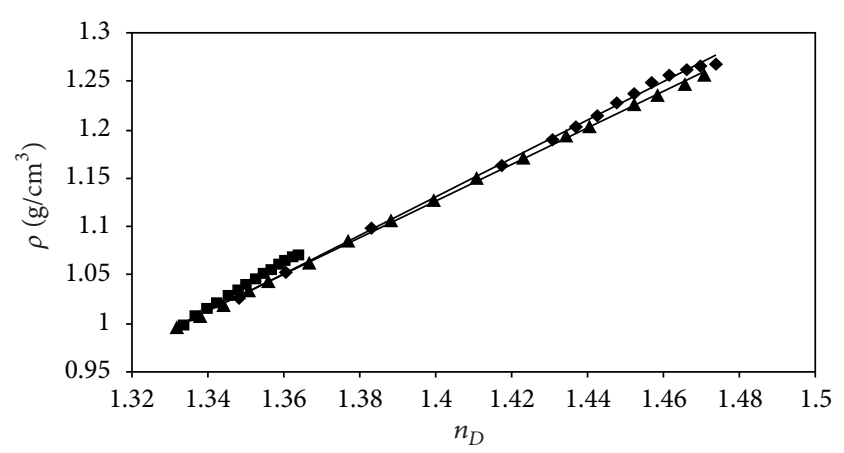

FIgURE 5: Variation of densities, $\rho$, against refractive indices, $n_{D}$, at $T(\mathrm{~K})=303.15$ for binary systems of: $\downarrow$, (water + [LCHCMH]); (water + D-sorbitol); $\mathbf{\Delta}$, (water + glycerol).

For aqueous solutions of glycerol (5) at $313.15 \mathrm{~K}$ has the general form:

$$
n_{D}=0.0102 c+1.3310
$$

According to (6), having the refractive index of aqueous solution of glycerol at $313.15 \mathrm{~K}$, we can obtain the molar concentration of the solution in the same temperature, and vice versa.

For aqueous solution of glycerol the calculated refractive indices according to (6) and the experimental ones at $313.15 \mathrm{~K}$ in different molar concentrations of glycerol are listed in Table 6. The low relative deviations for experimental and calculated values of $n_{D}$ for aqueous solution of glycerol indicate that the experimental values are well fitted in (5) and (6) at $313.15 \mathrm{~K}$.

Also as seen in Figure 5, for solution of this study the relation between density and refractive index is linear. These lines ( $\rho$ versus $n_{D}$ ) are close together. The relation between density and refractive index can be due to the interaction between the solute and solvent molecules. In these solutions the solvent is water and the kind of interaction between solute and solvent is the H-bond. Therefore, we expect the same results for variation of density versus refractive index. In Figure 5 we see the same slope of the lines $\left(\rho\right.$ versus $n_{D}$ ). Therefore, the quantities of slopes can be depend on the kinds of solvent-solute interaction.

A third-order polynomial was found to satisfactorily correlate the change of density with various compositions [28]:

$$
\rho=b_{\circ}+b_{1} x_{1}+b_{2} x_{1}^{2}+b_{3} x_{1}^{3}
$$

In this equation, $x_{1}$ is the mole fractions of [LCHCMH], $\mathrm{D}$-sorbitol, and glycerol, and $b_{\circ}, b_{1}, b_{2}$, and $b_{3}$ refer to the fit coefficients. Fit parameters are listed in Table 7 for the mixtures.

For different aqueous solutions in each temperature, $b_{\circ}$ in (7) is the density of pure water (solvent).

$$
x_{1}=0 \Longrightarrow \rho=b_{\circ} \text {. }
$$


TABLE 5: Value of constants $A_{n}, n_{D}^{*}$ (from (5) and relative deviation of $n_{D}^{*}$ for aqueous solution of [LCHCMH], D-sorbitol, and glycerol at various temperatures $(\mathrm{K})$.

\begin{tabular}{|c|c|c|c|c|c|}
\hline$T(\mathrm{~K})$ & System & $A_{n}(\mathrm{~L} / \mathrm{mol})$ & $n_{D}^{*}$ & $\begin{array}{c}n_{D}^{*} \\
\text { Literature }\end{array}$ & $\mathrm{RD}\left(\right.$ for $\left.n_{D}^{*}\right)$ \\
\hline 303.15 & \multirow{3}{*}[\mathrm{LCHCMH}]{+ water } & 0.0282 & 1.3324 & $1.3319^{\mathrm{b}}$ & 0.00038 \\
\hline 313.15 & & 0.0280 & 1.3309 & $1.3306^{\mathrm{b}}$ & 0.00023 \\
\hline 323.15 & & 0.0278 & 1.3299 & $1.3290^{\mathrm{b}}$ & 0.00068 \\
\hline 303.15 & \multirow{3}{*}{ D-sorbitol + water } & 0.0259 & 1.3318 & $1.3319^{\mathrm{b}}$ & 0.00008 \\
\hline 313.15 & & 0.0256 & 1.3306 & $1.3306^{\mathrm{b}}$ & 0.00000 \\
\hline 323.15 & & 0.0246 & 1.3296 & $1.3290^{\mathrm{b}}$ & 0.00045 \\
\hline 303.15 & \multirow{3}{*}{ glycerol + water } & 0.0104 & 1.3327 & $1.3319^{\mathrm{b}}$ & 0.00060 \\
\hline 313.15 & & 0.0102 & 1.3310 & $1.3306^{\mathrm{b}}$ & 0.00030 \\
\hline 323.15 & & 0.0100 & 1.3293 & $1.3290^{\mathrm{b}}$ & 0.00023 \\
\hline
\end{tabular}

TABLE 6: Experimental and calculated refractive indices $\left(n_{D}\right)$ from (6) and relative deviation of $n_{D}$ as function of molar concentrations of glycerol $(c)$ for aqueous solution of glycerol at $T=313.15 \mathrm{~K}$.

\begin{tabular}{cccccccc}
\hline $\begin{array}{c}c \\
(\mathrm{~mol} / \mathrm{L})\end{array}$ & $\exp$ & $\mathrm{cal}$ & $\mathrm{RD}\left(\right.$ for $\left.n_{D}\right)$ & $\begin{array}{c}c \\
(\mathrm{~mol} / \mathrm{L})\end{array}$ & \multicolumn{2}{c}{$n_{D}$} & \multicolumn{2}{c}{ exp $\left(\right.$ for $\left.n_{\mathrm{D}}\right)$} \\
\hline 1.00 & 1.3410 & 1.3408 & 0.00015 & 6.50 & 1.3975 & 1.3969 \\
2.00 & 1.3515 & 1.3510 & 0.00037 & 7.00 & 1.4025 & 1.4020 \\
3.00 & 1.3615 & 1.3612 & 0.00022 & 7.50 & 1.4075 & 1.4071 \\
4.00 & 1.3720 & 1.3714 & 0.00044 & 8.00 & 1.4125 & 1.4122 \\
5.00 & 1.3820 & 1.3816 & 0.00029 & 8.50 & 1.4175 & 1.4173 \\
6.00 & 1.3920 & 1.3918 & 0.00014 & 9.00 & 1.4230 & 1.4224 \\
\hline
\end{tabular}

TABLE 7: Coefficients $b_{i}$ of the polynomial (7), and relative deviation (RD) between $b_{\circ}$ (density of pure water in literature) and experimental $b_{\circ}$ (that obtain from (7) at various temperatures for different binary mixtures.

\begin{tabular}{|c|c|c|c|c|c|c|}
\hline$T(\mathrm{~K})$ & $b_{\circ}\left(\mathrm{g} / \mathrm{cm}^{3}\right)$ & $b_{1}\left(\mathrm{~g} / \mathrm{cm}^{3}\right)$ & $b_{2}\left(\mathrm{~g} / \mathrm{cm}^{3}\right)$ & $b_{3}\left(\mathrm{~g} / \mathrm{cm}^{3}\right)$ & $\begin{array}{l}b_{\circ}\left(\mathrm{g} / \mathrm{cm}^{3}\right) \\
\text { Literature }\end{array}$ & $\mathrm{RD}\left(\right.$ for $\left.b_{\circ}\right)$ \\
\hline \multicolumn{7}{|c|}{$[\mathrm{LCHCMH}](2)+$ water $(1)$} \\
\hline 303.15 & 1.0046 & 2.4795 & -6.3416 & 3.5316 & $0.99565^{\mathrm{a}}$ & 0.0090 \\
\hline 313.15 & 0.9965 & 2.8025 & -11.2350 & 20.0310 & $0.99221^{\mathrm{a}}$ & 0.0043 \\
\hline 323.15 & 0.9937 & 2.7695 & -11.1250 & 19.6010 & $0.98804^{\mathrm{b}}$ & 0.0057 \\
\hline \multicolumn{7}{|c|}{ D-sorbitol (2) + water (1) } \\
\hline 303.15 & 0.9898 & 4.3269 & -52.3920 & 14.9970 & $0.99565^{\mathrm{a}}$ & 0.0059 \\
\hline 313.15 & 0.9870 & 4.1404 & -48.5530 & 30.4230 & $0.99221^{\mathrm{a}}$ & 0.0053 \\
\hline 323.15 & 0.9827 & 4.1708 & -49.1770 & -44.9920 & $0.98804^{\mathrm{b}}$ & 0.0054 \\
\hline \multicolumn{7}{|c|}{ glycerol (2) + water (1) } \\
\hline 303.15 & 1.0023 & 0.8796 & -1.1677 & 0.5452 & $0.99565^{\mathrm{a}}$ & 0.0067 \\
\hline 313.15 & 0.9988 & 0.8683 & -1.1532 & 0.5390 & $0.99221^{\mathrm{a}}$ & 0.0066 \\
\hline 323.15 & 0.9944 & 0.8591 & -1.1427 & 0.5353 & $0.98804^{\mathrm{b}}$ & 0.0064 \\
\hline
\end{tabular}

Ref. [9].

${ }^{b}$ Ref. [28].

We calculate the relative deviation $(\mathrm{RD})$ between $b_{\circ}$ in literature (density of pure water [28]) and experimental $b_{\circ}$ (that obtained from (7)) and list those in Table 7. The low values of relative error in this case indicate that the experimental $b_{\circ}$ is very close to density of pure water. Thus, for these study mixtures (7) can be used in correlation of density with mole fraction of solute. The relative deviation (RD) for $b_{\circ}$ was calculated according to following equation:

$$
\mathrm{RD}=\left|\frac{b_{\circ(\mathrm{lit})}-b_{\circ(\exp )}}{b_{\circ(\mathrm{lit})}}\right|,
$$


where $b_{\circ \text { (lit) }}$ is the value of $b_{\circ}$ found in literature (density of pure water) and $b_{\circ(\exp )}$ is the value of $b_{\circ}$ from (7).

The RD for $n_{D}^{*}$ was calculated according to the following equation:

$$
\mathrm{RD}=\left|\frac{n_{D}^{*}-n_{D(c)}^{*}}{n_{D}^{*}}\right|,
$$

where $n_{D(c)}^{*}$ is the calculated value of refractive index of water from (5) and $n_{D}^{*}$ is the experimental value of refractive index of water (in literature) at the same temperature.

\section{Conclusions}

The experimental viscosities, densities, and refractive indices for the binary system of $([\mathrm{LCHCMH}]+$ water) and (Dsorbitol + water) at $(303.15,308.15,313.15,318.15$, and 323.15) and also densities, refractive indices data for (glycerol + water) at (303.15, 313.15, and 323.15) K were obtained over a wide range of composition. For aqueous solution of glycerol, from the experimental density and refractive index, values of excess molar volume and change of refractive index on mixing were calculated.

It was found that for aqueous solution of glycerol, all these calculated quantities for excess molar volume and change of refractive index on mixing are negative and positive, respectively. The Redlich-Kister polynomial equation was applied successfully for the correlation of $\Delta n_{D}$ and $V^{E}$.

\section{References}

[1] C. Yang, W. Xu, and P. Ma, "Thermodynamic properties of binary mixtures of $\mathrm{p}$-xylene with cyclohexane, heptane, octane, and N-methyl-2-pyrrolidone at several temperatures," Journal of Chemical and Engineering Data, vol. 49, no. 6, pp. 1794-1801, 2004.

[2] Y. F. Hu, "The thermodynamics of nonelectrolyte systems at constant activities of any number of components," Journal of Physical Chemistry B, vol. 107, no. 47, pp. 13168-13177, 2003.

[3] F. Koohyar, F. Kiani, S. Sharifi, M. Sharifirad, and S. H. Rahmanpour, "Study on the change of refractive index on mixing, excess molar volume and viscosity deviation for aqueous solution of methanol, ethanol, ethylene glycol, 1-propanol and 1,2,3-propantriol at $T=292.15 \mathrm{~K}$ and atmospheric pressure," Research Journal of Applied Sciences, Engineering and Technology, vol. 4, pp. 3095-3101, 2012.

[4] C. M. Romero, M. S. Páez, and D. Pérez, "A comparative study of the volumetric properties of dilute aqueous solutions of 1-propanol, 1,2-propanediol, 1,3-propanediol, and 1,2,3propanetriol at various temperatures," Journal of Chemical Thermodynamics, vol. 40, no. 12, pp. 1645-1653, 2008.

[5] P. Hynčica, L. Hnedkovsky, and I. Cibulka, "Partial molar volumes of organic solutes in water. XV. Butanediols(aq) at temperatures from $(298 \mathrm{~K}$ to $573 \mathrm{~K})$ and at pressures up to $30 \mathrm{MPa}$, Journal of Chemical Thermodynamics, vol. 38, no. 9, pp. 1085-1091, 2006.

[6] D. I. Sagdeev, M. G. Fomina, G. K. H. Mukhamedzyanov, and I. M. Abdulagatov, "Partial molar volumes of organic solutes in water. XV. butanediols(aq) at temperatures from ( $298 \mathrm{~K}$ to $573 \mathrm{~K}$ ) and at pressures up to $30 \mathrm{MPa}$," Journal of Chemical Thermodynamics, vol. 43, pp. 1824-1091, 2011.
[7] C. M. Romero and M. S. Páez, "Volumetric properties of aqueous binary mixtures of 1-butanol, butanediols, 1,2,4-butanetriol and butanetetrol at 298.15 K," Journal of Solution Chemistry, vol. 36, no. 2, pp. 237-245, 2007.

[8] E. Zorebski and B. Lubowiecka-Kostka, "Thermodynamic and transport properties of (1,2-ethanediol + 1-nonanol) at temperatures from (298.15 to 313.15) K,' Journal of Chemical Thermodynamics, vol. 41, no. 2, pp. 197-204, 2009.

[9] J. F. Comesaña, J. J. Otero, E. Camesella, and A. Correa, "Densities and viscosities of ternary systems of water + fructose + sodium chloride from 20 to $40{ }^{\circ} \mathrm{C}$," Journal of Chemical and Engineering Data, vol. 46, no. 5, pp. 1153-1155, 2001.

[10] D. R. Chiou, S. Y. Chen, and L. J. Chen, "Density, viscosity, and refractive index for water +2 -butoxyethanol and +2 (2-butoxyethoxy)ethanol at various temperatures," Journal of Chemical and Engineering Data, vol. 55, no. 2, pp. 1012-1016, 2010.

[11] M. L. Ge, J. L. Ma, and B. Chu, "Densities and viscosities of propane-1,2,3-triol + ethane-1,2-diol at $T=$ (298.15 to 338.15) K," Journal of Chemical and Engineering Data, vol. 55, no. 7, pp. 2649-2651, 2010.

[12] Q. S. Li, M. G. Su, and S. Wang, "Densities and excess molar volumes for binary glycerol + 1-propanol, + 2-propanol, + 1,2-Propanediol, and + 1,3-propanediol mixtures at different temperatures," Journal of Chemical and Engineering Data, vol. 52, no. 3, pp. 1141-1145, 2007.

[13] J. B. Raoof, R. Ojani, and M. Kolbadinezhad, "Electrocatalytic characteristics of ferrocenecarboxylic acid modified carbon paste electrode in the oxidation and determination of Lcysteine," Electroanalysis, vol. 17, no. 22, pp. 2043-2051, 2005.

[14] Y. F. Hu, Z. X. Zhang, Y. H. Zhang, S. S. Fan, and D. Q. Liang, "Viscosity and density of the nonelectrolyte system mannitol + sorbitol + sucrose $+\mathrm{H}_{2} \mathrm{O}$ and its binary and ternary subsystems at 298.15 K," Journal of Chemical and Engineering Data, vol. 51, no. 2, pp. 438-442, 2006.

[15] A. Collignan and A. L. Raoult-Wack, "Dewatering and salting of cod by immersion in concentrated sugar/salt solutions," Food Science and Technology, vol. 27, no. 3, pp. 259-264, 1994.

[16] K. S. D. Javaraman, K. D. Gupta, and N. B. Rao, "Effect of pretreatment with salt and sucrose on the quality and stability of dehydrated cauliflower," International Journal of Food Science \& Technology, vol. 25, no. 1, pp. 47-60, 1990.

[17] A. L. Raoult-Wack, "Recent advances in the osmotic dehydration of foods," Trends in Food Science and Technology, vol. 5, no. 8, pp. 255-260, 1994.

[18] M. K. Chun and H. Lee, "Phase equilibria of R22 (CHClF2) hydrate system in the presence of sucrose, glucose and lactic acid," Fluid Phase Equilibria, vol. 150, no. 151, pp. 361-370, 1998.

[19] R. C. Weast, CRC Handbook of Chemistry and Physics, CRC Press, New York, NY, USA, 59th edition, 1978.

[20] M. Windholz, The Merck Index, An Encyclopedia of Chemical, Drugs, and Biological, Merck \& Co. Inc, Rahway, NJ, USA, 10th edition, 1983.

[21] O. Redlich and A. T. Kister, "Algebraic representation of thermodynamic properties and the classification of solutions," Industrial \& Engineering Chemistry, vol. 40, pp. 345-348, 1948.

[22] G. A. Jeffery and W. Sanger, Hydrogen Bonding in Biological Structures, Springer-Verlg, Berlin, Germany, 1991.

[23] M. V. Rathnam, R. K. R. Singh, and M. S. Kumar, "Excess volumes of binary solutions of methyl formate, ethyl formate, 
propyl formate, and benzyl acetate with bromo-, chloro-, and nitrobenzenes at $(303.15,308.15$, and 313.15) K," Journal of Chemical and Engineering Data, vol. 53, no. 1, pp. 265-270, 2008.

[24] A. F. Ribeiro, E. Langa, A. M. Mainar, J. I. Pardo, and J. S. Urieta, "Excess molar enthalpy, density, and speed of sound for the mixtures â-pinene + 1- Or 2-pentanol at $(283.15,298.15$, and 313.15) K," Journal of Chemical and Engineering Data, vol. 51, no. 5, pp. 1846-1851, 2006.

[25] C. Yang, H. Lai, Z. Liu, and P. Ma, "Density and viscosity of binary mixtures of diethyl carbonate with alcohols at (293.15 to 363.15$) \mathrm{K}$ and predictive results by UNIFAC-VISCO group contribution method," Journal of Chemical and Engineering Data, vol. 51, no. 4, pp. 1345-1351, 2006.

[26] A. J. Treszczanowicz, O. Kiyohara, and G. C. Benson, "Excess volumes for $n$-alkanols $+n$-alkanes IV. Binary mixtures of decan-1-ol $+n$-pentane, $+n$-hexane, $+n$-octane, $+n$-decane, and $+n$-hexadecane," The Journal of Chemical Thermodynamics, vol. 13, no. 3, pp. 253-260, 1981.

[27] H. Shekaari and F. Jebali, "Densities, viscosities, electrical conductances, and refractive indices of amino acid + ionic liquid ([BMIm]Br) + water mixtures at $298.15 \mathrm{~K}$," Journal of Chemical and Engineering Data, vol. 55, no. 7, pp. 2517-2523, 2010.

[28] T. Y. Wu, B. K. Chen, L. Hao, K. F. Lin, and I. W. Sun, "Thermophysical properties of a room temperature ionic liquid (1-methyl-3-pentyl-imidazolium hexafluorophosphate) with poly(ethylene glycol)," Journal of the Taiwan Institute of Chemical Engineers, vol. 42, no. 6, pp. 914-921, 2011. 

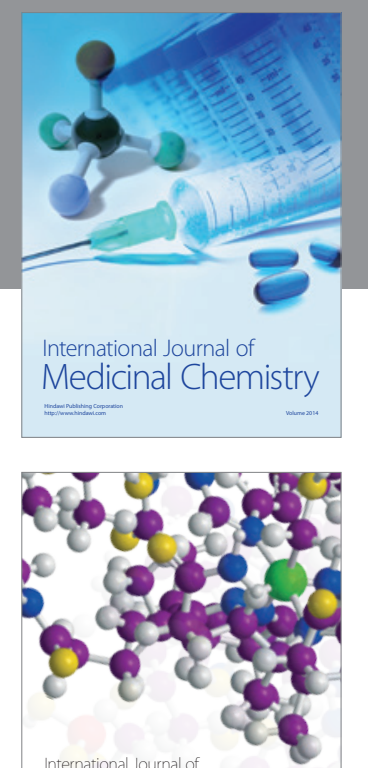

\section{Carbohydrate} Chemistry

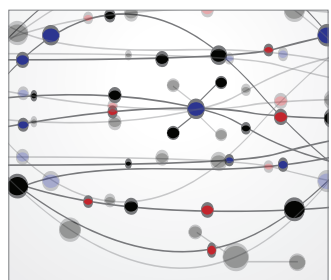

The Scientific World Journal
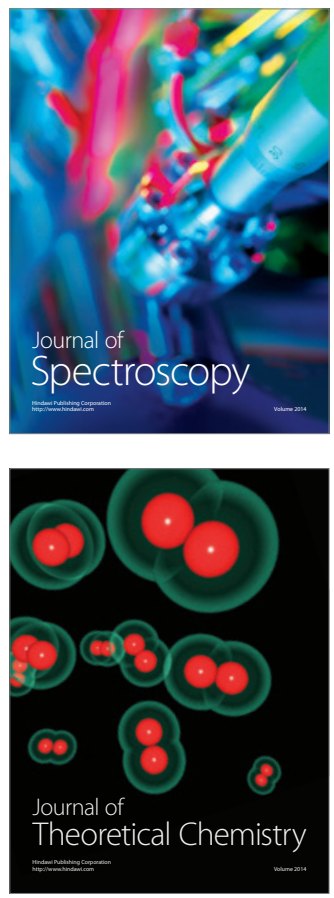
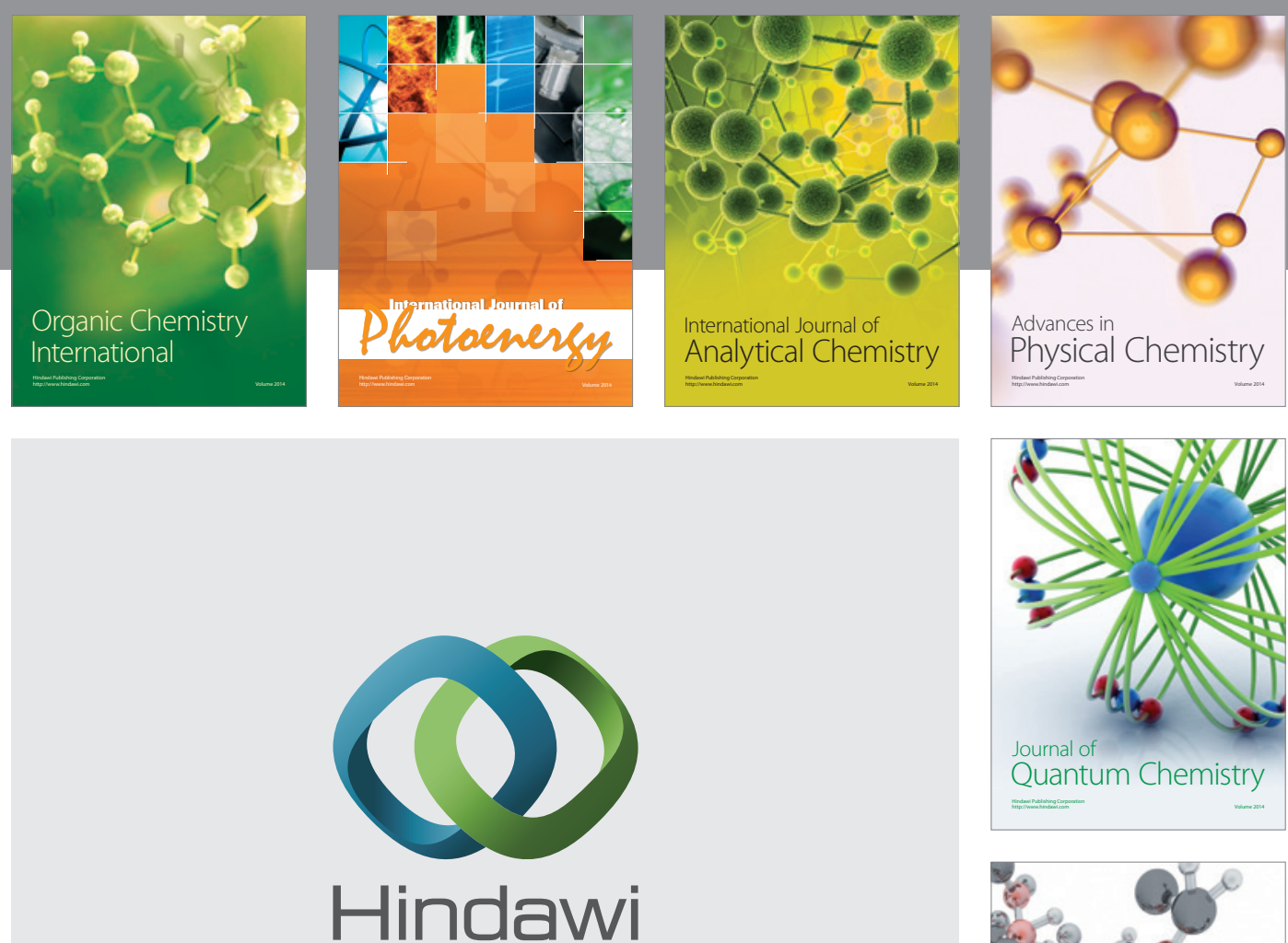

Submit your manuscripts at

http://www.hindawi.com

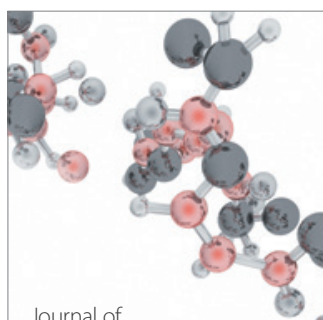

Analytical Methods

in Chemistry

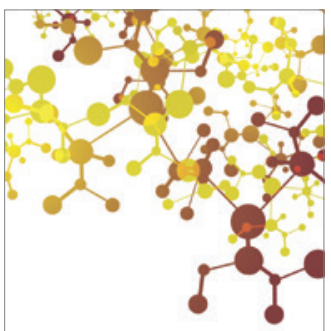

Journal of

Applied Chemistry

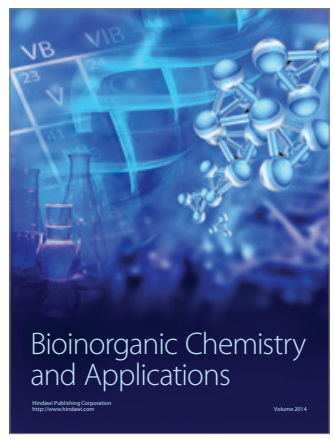

Inorganic Chemistry
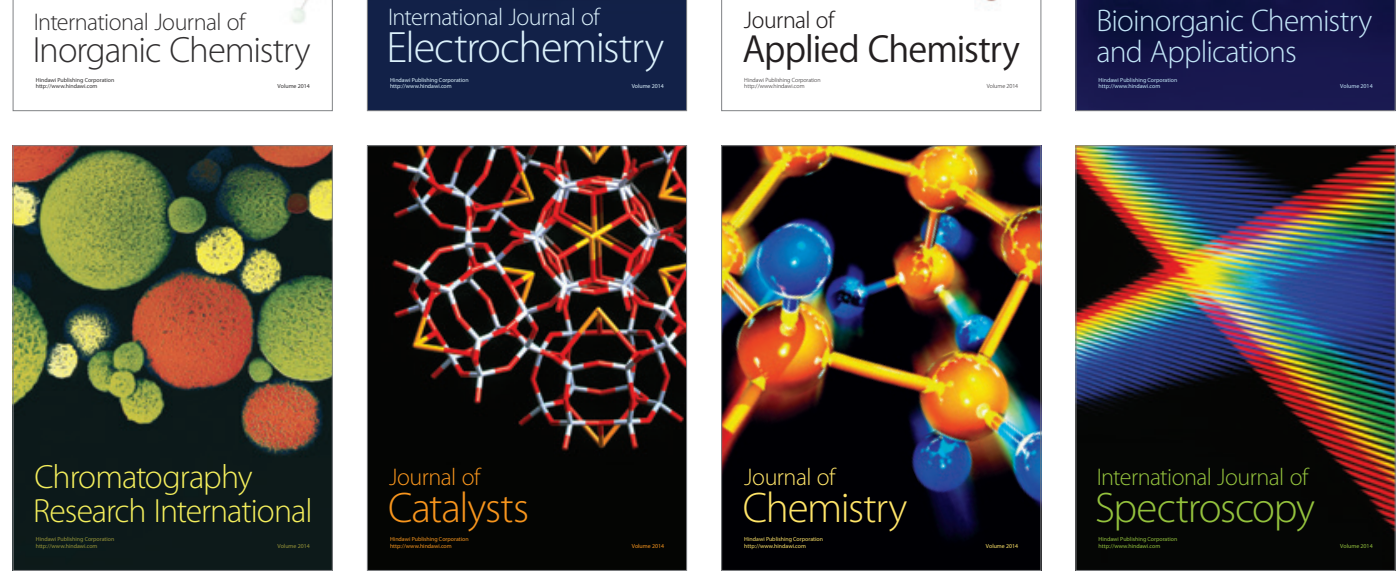